\title{
APROXIMACIÓN AL ESTUDIO DE LOS TAGARENOS EN BIZERTA A PARTIR DE UNA ESTELA FUNERARIA RECIÉN DESCUBIERTA
}

\author{
Abdel-Hakim Slama-Gafsi*
}

Los andalusíes o descendientes de los moriscos llegados de España se instalaron al norte de Bizerta, fuera del recinto urbano amurallado, justo al pie de las murallas y frente al mar. Bizerta conserva hasta hoy día el importante barrio de los Andalusíes (Hamdlis) ${ }^{1}$.

A lo largo de este trabajo voy a mostrar el impacto de los descendientes de los moriscos emigrados en Bizerta a través de los documentos materiales e inmateriales disponibles.

\section{UN TAGARENO EN UN TEXTO EPIGRÁFICO POR PRIMERA VEZ}

A finales de marzo de 2006, durante los trabajos de la construcción del teatro en el antiguo cementerio de Sidi Bouhdid o Jbibina, descubrí una porción de lápida en el área excavada por las máquinas de la empresa. Este cementerio, transformado en bosque durante los años ochenta, está situado frente al fuerte de los Andalusíes y cerca del barrio de los Andalusíes o Hamdlis.

La lápida encontrada está realizada en piedra caliza blanca o Kaddal y tiene unas dimensiones de $47 \mathrm{~cm}$ de altura, $16 \mathrm{~cm}$ de anchura y $14 \mathrm{~cm}$ de grosor. Posee un epígrafe en árabe tunecino en su cara plana y pulida. La parte superior se encuentra mutilada.

La base inferior, de $14 \mathrm{~cm}$ de anchura por $7 \mathrm{~cm}$ de altura, estaba fijada a la placa de la tumba. La segunda, superpuesta sobre la primera, de $9 \mathrm{~cm}$ de anchura por $6 \mathrm{~cm}$ de altura y está decorada con un borde, en cada lado, en forma de ángulo. Esta estela tiene un campo epigráfico de $24,5 \mathrm{~cm}$ de altura por $11 \mathrm{~cm}$

\footnotetext{
* Instituto Nacional del Patrimonio, Túnez.

1. J.D. LATHAM, «Towards a study of Andalusian Immigrations and its place in Tunisian History», Les Cahiers de Tunisie, V, 1957, pp. 203-252.
} 


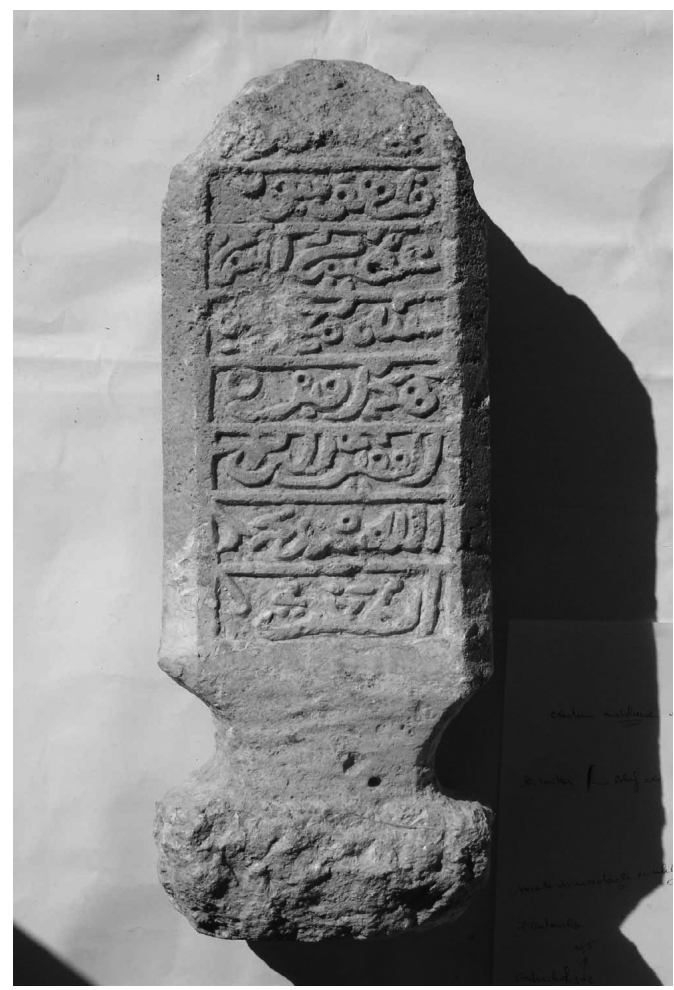

de anchura, rodeado por una moldura en relieve de $1 \mathrm{~cm}$ El texto, formado por siete líneas de carácteres cursivos en relieve, está dispuesto dentro de bandas o cajas. En general las líneas se conservan en buen estado y poseen puntos sin vocales y sin errores gramaticales. Cabe señalar que la tercera línea se encuentra incompleta y las letras 7 y 8 están borradas por el tiempo. Algunas letras, de un esbelto y elegante trazado, tienen una decoración "geométrica" estilizada. Esta escritura cursiva de tipo espontáneo es muy rara en el corpus tunecino.

En primer lugar aparece la aleya 67 y 68 de la sura XXXVIII («Sad»), seguida directamente por la fórmula habitual acompañada del nombre del difunto:

1. Diles: El mensaje

2. es un mensaje grave y vosotros

3. Desdeñáis oírlo.

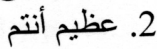

4. Esta es la tumba del

5. Indigente que tiene necesidad

6. de Dios, Muhammad Ibn Muhammad

7. At Tagrī

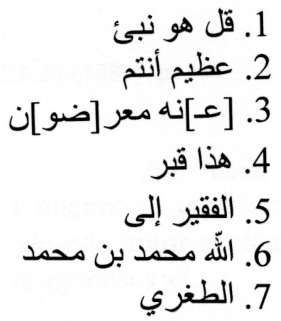


Se puede constatar que el texto se reduce a una breve alusión al finado y no contiene la profesión o título del difunto, la fecha, la basmala: "en nombre de Allah, el Clemente, el Misericordioso", la eulogia y la profesión de fe. Como he señalado anteriormente, falta la parte superior de lápida y a la luz de estas y otras anotaciones en otras lápidas similares me inclino a pensar que la basmala estaría en esta parte de la lápida.

Los posibles indicios para fechar y establecer una cronología de la lápida son mínimos. Por sus caracteres externos se puede fechar dentro de los límites del siglo XVII. La grafía es diferente de la escritura de las inscripciones conmemorativas oficiales del mismo siglo en Túnez y en los pueblos andalusíes ${ }^{2}$. La escritura de esta lápida no puede ser de la misma serie.

A pesar de su limitado valor estético y religioso, esta lápida nos indica una información muy importante acerca del origen del difunto. Es la primera vez que tenemos un "Tagri" o tagarino en un documento pétreo.

\section{TAgARENOS EN TúNEZ}

Se observa que el apellido del difunto se escribe con b o t y no con ث. La misma observación se aplica también acerca del apellido del copista del manuscrito hecho en el año 1070/1659 y conservado en la gran mezquita de Testour. Este copista se llama Muhammad Ibn Muhammad Balansian aț-Tagrī atTastūrī ${ }^{3}$. Los documentos archivísticos estudiados por Rached Limam mencionan el apellido Tagarine al Andalusi en el año 1863ㄴ Ahmad Ibn Tagarine al Andalusi tenía una panadería en el pueblo morisco de Medjez el Bab . $^{5}$

Las informaciones sobre la palabra Tagrī son frecuentes. El viajero francés Thomas d'Arcos, que visitó Testour en 1631, señala: “Sur cette dernière branche [de la Medjerda] les Andaluzes, Tagarins et Catalans ont fondé plusieurs villages"6 .

2. A. Slama-GafSI, «La médersa des Moriscos-Andalous à Tunis», Sharq Al-Andalus. Estudios árabes, 5, 1988, pp. 169-180; id., «Sobre las fuentes públicas en los pueblos moriscos-andalusíes en Tunicia en los siglos XVII, XVIII y XIX», Homenaje al Prof. L.P. Harvey, Sharq Al-Andalus. Estudios Mudéjares y Moriscos, 16-17, 1999-2002, pp. 313-342; id., "Chrétiens convertis et moriscos-andalous en Tunisie au XVIIe siècle d'après les documents épigraphiques», Chrétiens et musulmans à la Renaissance, Tours, 1985, pp. 487-505; id., "Túnez y España en el siglo XVII, a través de los moriscos en Túnez», Túnez. Tierra de Culturas, Barcelona-València, 2003, p. 138; id., «Stèle funéraire», en Tunisie en terre de rencontres et de civilisations, Túnez, 1992, p. 283; SLAMA-GAFSI y A. DAOULATLI, «Inscription à la mosquée andalouse d'El Aliya», en M. de EPALZA y R. PETIT, Etudes sur les moriscos-andalous en Tunisie, Madrid, 1973, pp. 285-290.

3. A. HamrounI, «Fahris Mahtuṭ āt Testūr», Al Hidaya, 1977, p. 41.

4. «Al andalusiyyūn fī bilād at-Tūnisiyya fī-l-qarn XIX», Revue d'Histoire Maghrébine, 23-24, 1981, p. 308.

5. Archives Nationales Tunisiennes, Registre 1862, p. 2, año 1254/ 1838

6. A. SADAOUI, Testour du XVIIe au XIXe siècle, histoire architecturale d'une ville morisque en Tunisie, Túnez, 1996, p. 39. 
En la obra del trinitario español Francisco Ximénez podemos encontrar también informaciones importantes relativas a esta palabra como en el testimonio de este autor acerca de Testour en 1720: "Hay muchos de estos moros andaluces, tagarinos y aragoneses" ${ }^{\prime 7}$.

Podemos encontrar también informaciones del mismo autor en su obra Diario de Túnez acerca de los tagarinos del pueblo de Solimán: "Está al presente habitado de 300 familias de moros andaluces y tagarinos y 600 alarbes" ${ }^{8}$. El testimonio de Ximénez está confirmado por el viajero francés Peysonnel en el año 1724: "Elle fut rebâtie en 1611 par les Maures Andaloux et Tagarins" ${ }^{\text {. }}$ Ximénez evoca el mismo tema en su obra Colonia trinitaria de Túnez: "Ordinariamente los llaman Andaluces porque vino de la Andalucía la mayor parte, pero se distinguen entre ellos según las provincias de España donde tienen el origen. Hay Catalanes originarios de Cataluña, Tagarinos del territorio de Tarragona, y aún por este nombre entienden todos los Aragoneses..."10.

Según el arqueólogo francés Georges Marçais, la mezquita mayor de Testour se alza en el barrio de los Tagarinos y fue edificada en el siglo XVII por Muhammad Tagarino, según la tradición ${ }^{11}$.

Por otro lado, Georges Marçais confirma que la fachada de esta mezquita tiene la misma decoración que las fachadas mudéjares de Aragón ${ }^{12}$. Los autores del libro La cultura islámica en Aragón abordan el tema más detalladamente: "En Aragón, a diferencia de otros países hispanos, el ramo de la construcción estaba prácticamente copado por la minoría morisca (al menos en las comarcas donde habitaban), por lo que trasladaron todas sus técnicas constructivas desde Aragón a Túnez. Esas técnicas constituyeron en Tunicia importantes novedades, como la cubierta con tejado en lugar de azotea, el ladrillo y el aparejo concertado en muros de carga, plantas mixtas (cuadrada y octogonal) en alminares, elementos ornamentales renacentistas y barrocos, etc." ${ }^{\prime 3}$.

Por otro lado, muchos moriscos españoles recién emigrados aparecen en los archivos del consulado de Francia en Túnez, estudiados magistralmente por Epalza, como tagarinos. Mustafa de Cardenas aparece en 1635 como “jefe

7. M. de EpalzA, «Nuevos documentos sobre descendientes de moriscos en Túnez en el siglo XVIII», Studia historica et philologica in honorem M. Batllori, Roma, 1984, p. 219; M. DE EPALZA y A. SlAmA-GAFSI, El español hablado en Túnez por los moriscos (siglos XVII-XVIII), Valencia, 2010, p. 29. L.F. BERNABÉ PONS, El cántico islámico del morisco hispano-tunecino Taybili, Zaragoza, 1988, p. 23.

8. M. de Epalza, op. cit., p. 221.

9. M. de Epalza y R. Petit, op. cit., p. 136.

10. M. de EpalzA, op. cit., p. 225.

11. «Testour et sa grande mosquée. Contribution à l'étude des Andalous en Tunisie», Revue Tunisienne, 1942, p. 158

12. Ibid., p. 160.

13. J.L. Corral, F. Javier Peña, C. Bressel, M. Cervera, C. Carcía y J.M. Pinilla, La cultura islámica en Aragón, Zaragoza, 1989, p. 132. 
de la nación andaluza y tagarenos"14; Baba Alli Andalusi en 1624, Aggi Mamet en 1635, osta Mamet Rombos en 1630, figuran como tagarinos ${ }^{15}$.

Los moriscos se identifican también por su origen regional en España. Unos son originarios de Aragón: Mahamet Andaluz Aragonés, Mahmet Jasnadal, Miquel Anriques, Fatima Saragosana, Amat Saragouzano de Zaragoza. Hay también catalanes (Ali Catalán) o mallorquines (Mahamet Mallorquin) ${ }^{16}$. Y aparecen otros apellidos aragoneses como Tarwil (de Teruel), Churia (de Soria)... ${ }^{17}$.

Este tema ha merecido la atención de Antonio Domínguez Ortiz y Bernard Vincent, que han acumulado pruebas -con una argumentación muy convergente- sobre los moriscos poco antes de la expulsión: "Habría entonces, en Aragón, 63.491 moriscos poco antes de la expulsión... La mayoría se agrupaban a lo largo del Ebro y de sus afluentes... En Cataluña los moriscos fueron siempre poco numerosos, ... de siete a ocho mil... La población morisca de la actual provincia de Tarragona se eleva a unos 5.650 individuos" ${ }^{18}$.

El apellido Tagarino o Tagareno parece provenir de la palabra árabe Thagr o frontera del Islam, como lo confirma Francisco Franco ${ }^{19}$, "por lo que podemos concluir que el difunto es de origen fronterizo o Thagri" "20. "Los tagarinos son los habitantes de las regiones fronterizas islámicas, Thugur o marcas vecinas de territorios no gobernados por autoridades musulmanas" ${ }^{21}$.

Según el arqueólogo francés G. Marçais: “Le pays du Thaghrînn peut aller du centre de la vieille Castille aux Pyréneés, ou commencer à la rive gauche de l'Ebre, ou se limiter à l' Aragon. Les Tagarinos seront plus proprement et stricto sensu les Musulmans Aragonais" 22 .

Epalza ha abordado este problema de los tagarinos de forma más detallada a partir de documentos árabes y españoles y ha mostrado que "En España había servido para designar especialmente a Aragón, donde había una importante población musulmana bajo dominio cristiano" ${ }^{\prime 23}$. El mismo autor se ha dedicado a precisar también la relación entre moriscos y tagarinos: “Los moriscos se identificaban también por su origen regional en la Península: ... 'tagarenos' tratándose de la Corona de Aragón (Aragón, Baleares, Cataluña,Va-

14. M. de EpAlZA, «Moriscos y andalusíes en Túnez durante el siglo XVII», Al-Andalus, XXXIV /2, 1969, p. 254.

15. Ibid., pp. 254, 264 y 279.

16. M. de Epalza y A. Slama-GafSI, op. cit., pp. 494, 515, 482 y 503.

17. A. SERnA, Imágenes de Túnez, Madrid, 1979, p. 269.

18. Historia de los moriscos. Vida y tragedia de una minoría, Madrid, 1978, p. 77.

19. Vías y defensas andalusíes en la marca oriental, Alacant, 1995, p. 173.

20. M. de EPAlZa y A. Slama-GafSi, op. cit., p. 37.

21. M. de EPAlZA, «Moriscos y andalusíes...», p. 254.

22. Ibid., p. 158.

23. M. de EpalzA, «Moriscos y andalusíes...», p. 254. 
lencia y probablemente Navarra)" ${ }^{24}$. Y volvía sobre el mismo tema en la introducción del libro de Luis F. Bernabé Pons, El cántico islámico del morisco hispanotunecino Taybili diciendo: "Tagarinos se refiere a los musulmanes del valle del Ebro o Marca superior ath-Thagr Al-Ala; y aragoneses es, en resumen, lo que define la mayoría de los moriscos" ${ }^{25}$.

Esta distinción se manifiesta también al nivel lingüístico según el mismo autor: "Hay testimonios de viajeros europeos que confirman que en algunos pueblos (Testur, Solimán...) se seguía hablando y contando en español, tanto en castellano-aragonés como en catalán-valenciano" ${ }^{26}$.

\section{¿TAGARENOS EN BIZERTA?}

Bizerta representaba una seria amenaza para la navegación española en el Mediterráneo y para la seguridad de los dominos reales como Sicilia, Cerdeña y Nápoles ${ }^{27}$. Con ocasión de la campaña de conquista del reino de Túnez, Bizerta fue ocupada por las tropas españoles de junio de 1535 a septiembre de 1573. Pero los turcos recuperaron esta plaza abandonada definitivamente por el monarca Carlos V en el año 1574.

Bizerta se transformó rapidamente en una base de defensa del territorio tunecino contra posibles ataques marítimos extranjeros, constituyendo la marca superior (Al-Thagr al-'Alà). Este nombre distintivo se conserva hasta al protectorado francés en 1881.

Para controlar este espacio accesible, rico y estratégico, tener relación privilegiada con la capital, facilitar las relaciones entre Bizerta y Túnez, y asegurar la ruta que unía las dos ciudades con los importantes puertos (Ghar el Melh o Porto Farina ${ }^{28}$, Raf Raf, Ras Djebel, Metline...) y los pueblos moriscos (Kalaat Al Andalus, Alia...) , el poder político turco realizó diversas obras públicas (puentes, calzadas). El puente sobre el río Medjerda cerca del pueblo morisco Kalaat Al Andalus constituye un testimonio elocuente de esta visión política ${ }^{29}$.

Estas ricas comarcas atrajeron a los moriscos inmigrantes. Para Uthman Dey (1598-1610), gobernador de la provincia (o wilayat) en nombre del poder político y militar de Istanbul, estos moriscos eran “jenízeros sin sueldo" ${ }^{30}$. Rápi-

24. M. de Epalza y A. Slama-Gafsi, op. cit., p. 36.

25. P. 23.

26. «Los moriscos o andalusíes en la historia vivida por los tunecinos», en Túnez tierra de culturas..., p. 149.

27. J.B. VILAR, Mapas, planos y fortificaciones hispánicos de Túnez (S.XVI-XIX), Madrid, 1991, p. 360.

28. A. Slama-Gafsi, Ghar El Melh, Túnez, 2008, p. 16.

29. A. SLAMA-GAFSI, «Le pont sur la route de Tunis à Bizerte: est-il une œuvre morisco-andalouse?», Mélanges Prof. Machiel Kiel, Zaghouan, 1999, pp. 309-320.

30. J.D. LATHAM, «Contribution à l'étude des Immigrations andalouses et leur place dans l'histoire de la Tunisie», en M. de Epalza y R. PetrT, op. cit., p. 41. 
damente Bizerta se transformó en el primer puerto militar del reino de Túnez para convertirse progresivamente en la principal base del corso tunecino del Mediterráneo occidental. Esta actividad militar y corsaria ha dejado cierta documentación a partir del siglo XVII ${ }^{31}$.

Sin embargo, desafortunadamente los estudios especializados sobre estos aspectos no abundan. Los documentos archivísticos consultados me han permitido conocer dos corsarios tunecinos de origen morisco en Bizerta en el siglo XIX, Marco y Forsado ${ }^{32}$.

Por lo que refiere a los descendientes de los moriscos no tenemos muchas informaciones. Los documentos archivísticos del consulado francés en Túnez, estudiados por Míkel de Epalza, mencionan el papel desempeñado por la morisca Fatima Buena en el año $1630^{33}$. Por su parte, otros documentos tunecinos, estudiados por Rached Limam a base de censos realizados entre 1855 y 1862, revelan que el número de andalusíes se reduce a 38 de un total de 1.366 habitantes. Bizerta contaba con 11 familias moriscas. Hay solamente una que tiene un apellido de clara ascendencia española (María) ${ }^{34}$.

Basándonos en la consulta de las fuentes arqueológicas, podemos saber que la fuente pública de Youssef Dey (1610-1637), situada muy cerca del puerto, fue construida por el maestro de obra (Mu'allam) 'Alī Ibn Dissīm ${ }^{35}$ al Andulsī en el año 1626. Esta fuente pública es uno de los más bellos monumentos arquitectónicos del legado morisco en Túnez. Se caracteriza por su precioso aparejo de dovelas de mármol alternas, negras y blancas, sus tejas redondas de color verde, su arco delimitado por dos columnas de mármol con capiteles de estilo hafșī. Su intradós está decorado con una hermosa inscripción en árabe y en osmanlî́ ${ }^{36}$.

Además de los aspectos mencionados relativos a los moriscos, tenemos algunas informaciores acerca de la población en Bizerta. Según la crónica de Sandoval, Bizerta no pasaba de ser en 1534 un "pueblo de ochocientos vecinos" ${ }^{37}$. En el año 1587, contaba con cinco mil habitantes, según las informaciones de Lanfreducci y Bosio $^{38}$. En el año 1624, Salvago confirma este número ${ }^{39}$. Un siglo después el trinitario español Francisco Ximénez afirma durante su visita en

31. N. DJELLOUL, Les fortifications côtières ottomanes de la Régence de Tunis (XVIe-XIXe siècles), Zaghouan, 1995, p. 159.

32. A. SlAmA-GAFSI, Binzart wal bahr (Bizerta y el mar), Bizerta, A.S.M. de Bizerta, p. 26 (sin fecha).

33. «Moriscos y andalusíes...», p. 262.

34. Ibid., p. 309.

35. M. de Epalza y A. Slama-Gafsi, op. cit., p. 485.

36. A. SlAmA-GAFSI, «Túnez y España...», p. 141.

37. J.B. VILAR, op. cit., p. 356.

38. "Costa e discorsi di Barberia», trad. de P. Granchamp, Revue Africaine, 322, 1925, p. 133.

39. «Africa overo Berbaria», trad. de P. Grandchamp, «Une mission délicate en Barbarie au XVIIe siècle», Revue Tunisienne, XLIV, 1937, p. 133. 
1726: "Bizerta es habitada de turcos, moros andaluces y beduinos. Los Andaluces serán cien familias" ${ }^{\prime 0}$. A través del informe del comandante militar francés Perrier, sabemos que en Bizerta había en 1878 cuatro mil habitantes. La población en el barrio de los Andalusíes alcanzaba los 300 habitantes $^{41}$. En 1975 Bizerta contaba con 13.559 habitantes y 1.441 individuos en el barrio de los Andalusíes ${ }^{42}$.

Como se ha visto, la documentación disponible no puede reflejar muy bien la situación de los andalusíes en Bizerta y sus orígenes. El estudio del urbanismo en el barrio de los Andalusíes puede iluminar un poco este problema.

Como es sabido la llegada de los moriscos a Túnez a principios del siglo XVII contituyó un acontencimiento importante en este sentido. Se le atribuye la puesta en valor de regiones arruinadas por la guerra hispanoturca y el desarrollo de un urbanismo completamente ajeno al del país. Los moriscos procedentes de España desarrollaron un modelo de espacio urbano diferente del que existía allí.

Actualmente este espacio urbano se articula en torno a una vía principal más o menos rectilínea, cruzada a derecha por varias calles secundarias casi rectilíneas de una manera más o menos ortogonal. Este trazado regular y geométrico da lugar a manzanas de formas rectangulares de talla similar. Las parcelas yuxtapuestas con sus patios son de forma regular.

Delante de la única mezquita del barrio de los Andalusíes había una pequeña plaza más o menos regular decorada con una fuente pública que desapareció durante los trabajos de la construcción del muro que separaba el barrio de los Andalusíes del cementerio del 'Aïn.

Hay que hacer notar que en este barrio no podemos encontrar el dédalo de calles, callejuelas irregulares, estrechas y callejones sin salida que caracterizan las otras partes de la ciudad (la Medina, la Kasbah y la Ksibah) y las medinas o ciudades árabes en general. Conviene señalar aquí que los moriscos pusieron en valor regiones arruinadas y desarrollaron un urbanismo ajeno al país.

Además de los aspectos mencionados, una descripción anónima de 1573 nos presenta la ciudad de Bizerta como "población de medio porte pero bien fortificada y con espléndido y concurrido puerto" ${ }^{43}$. Por otro lado, en un plano hecho en 1562 por Paolo Forlani, el litoral aparece protegido por torres y dominado por un castillo sobre una empinada roca ${ }^{44}$. En otro plano de 1613 Bizerta figura con su puerto fortificado, un canal de acceso, su bahía y su albufera ${ }^{45}$.

40. M. de Epalza, «Nuevos documentos...», p. 216.

41. N. Dougu, H. Bouaita, A. Braham y M. Ben Jaloul, Bizerte. Idendité et mémoire, Bizerte, 2000, p. 27 y 49 .

42. Sauvegarde et Mise en Valeur de la Médina de Bizerte, p. 7 (sin lugar, sin fecha).

43. J.B. VILAR, op. cit., p. 361.

44. Ibid., p. 354, foto 284 .

45. Ibid., p. 364, foto 296 . 


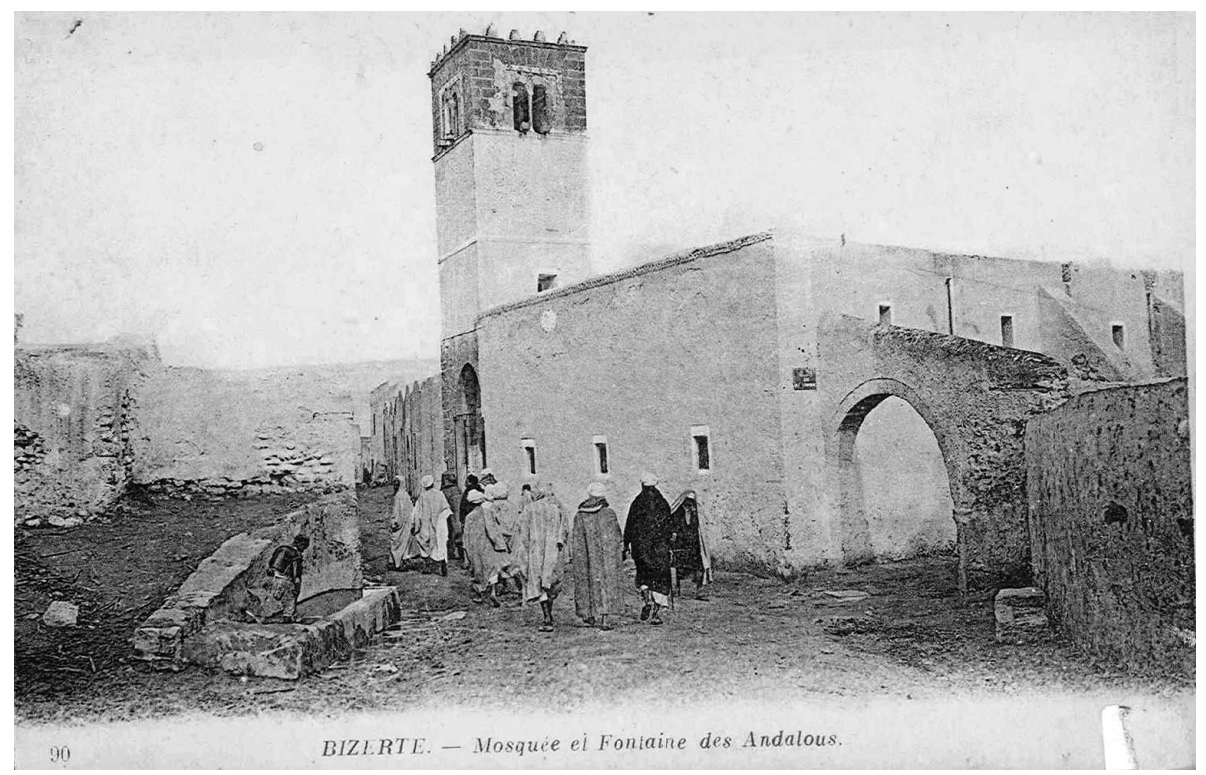

En efecto, Bizerta aparece en un plano hecho antes del protectorado francés (1881) y sobre un cabo y protegida por una poderosa muralla ${ }^{46}$, flanqueada por ocho torreones, y acostada al fuerte de España o fuerte de los Andalusíes, y por la ciudad satélite de la Kasbah completamente amurallada. La muralla norte se desarrolla en línea recta, flanqueada al noroeste por el fuerte de España o fuerte de los Andalusíes y da acceso al barrio de los Andalusíes a través de la puerta de los Andalusíes, hoy desaparecida ${ }^{47}$. Esta muralla, construida entre 1750 y 1753, según la obra de Djelloul ${ }^{48}$, está provista de un pasaje de ronda que domina toda la ciudad y todos los contornos.

Los documentos estudiados por Harvey nos proporcionan otras informaciones acerca de la contribución de los moriscos a estas obras. Según el cronista morisco Aḥmad al Hadjarī al Andalusī, alias Ehmad Bejarano, es el arquitecto morisco Al Hadj Mūsa, conocido como Yamiro al Andalusī al Garnațī, quien restauró el puerto de Bizerta durante el reino de Mūrad Dey (1637-1640), gobernador de la provincia turca de Túnez ${ }^{49}$. El fuerte de España, llamado la

46. N. Dougui et al., op. cit., p. 48.

47. Ibid., pp. 27 y 58.

48. N. DJelloul, op. cit., t. 1, p. 165, J.B. VILAR, op. cit., p. 359.

49. «The morisco who was Mulay Zaydan's spanish Interpreter Ahmed ben Qasim Ibn al-Faqih Qasim ash-Shaikh al Hajari al-andalusi», Miscelánea de Estudios Árabes y Hebraicos VIII/1, 1959 , p. 78. 


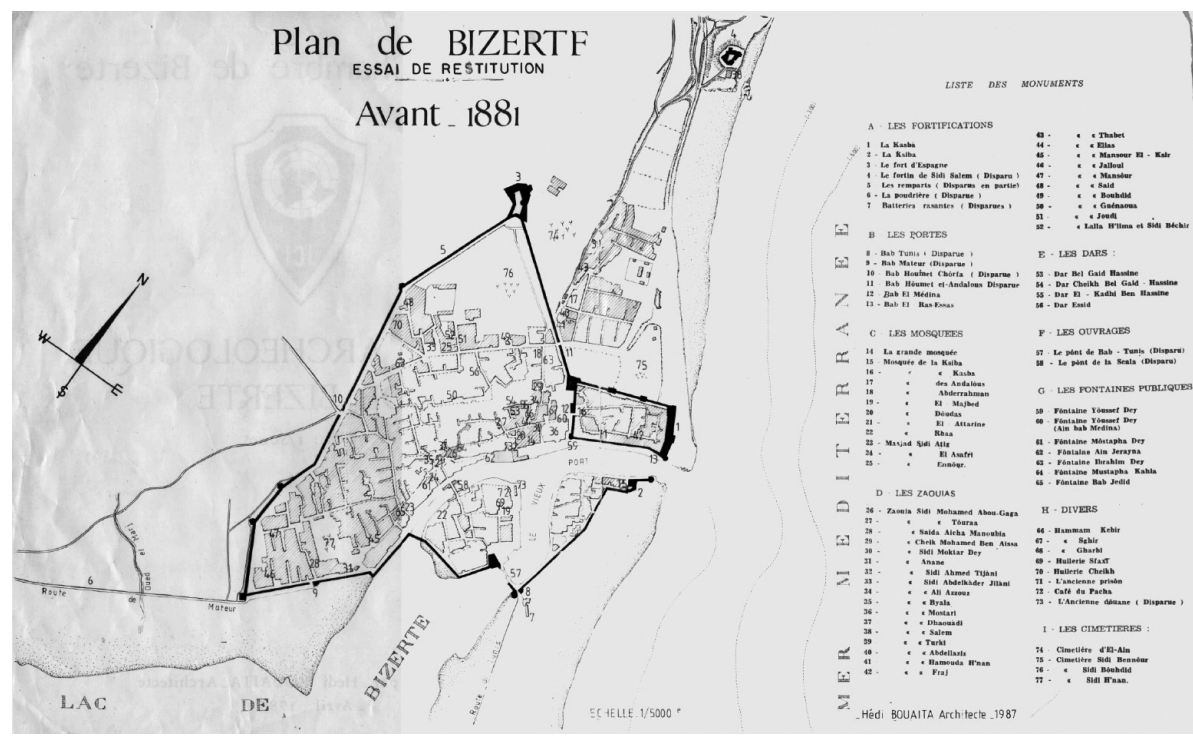

"qalaa" en los documentos turcos estudiados por A. Temimi ${ }^{50}$, fue construido sobre una colina o kudya por el caid Ferrat o Farhat, según las informaciones de los viajeros Lanfreducci y Bosio en el año $1587^{51}$. A las órdenes de Ily Ali (Elchi Ali, convertido al islam), esclavo calabrés y pachá de Argel en el año 1570, este fuerte fue terminado probablemente por los españoles que ocuparon la ciudad entre junio y septiembre de 1573 o por los moriscos ${ }^{52}$.

Este fuerte, que tenía la forma de una estrella de cinco puntas, típica de los fuertes militares españoles de la época, puede ser una obra de los moriscos tagarenos refugiados en Bizerta después de la expulsión. Un indicio importante puede confirmar esto. Como he señalado, la lápida funeraria fue descubierta en el cementerio de Sidi Bouhdid, situado frente al fuerte de los Andalusíes y junto al cementerio del 'Aïn o el cementerio de los Andalusíes. Estos dos cementerios están separados solamente por la muralla noreste que va del fuerte de los Andalusíes hasta la muralla de la Kasbah.

A la luz de estas observaciones puedo decir que los dos cementerios, el fuerte de los Andalusíes y el barrio de los Andalusíes han constituido un conjunto unido, dominado probablemente por los moriscos tagarenos vecinos del difunto.

50. Dirasat fi at-tarikh al utmani, Túnez, Fondation Temimi, 2009, p. 235.

51. Ibid.

52. N. DJelloul, op. cit., t. 1, p. 172. 


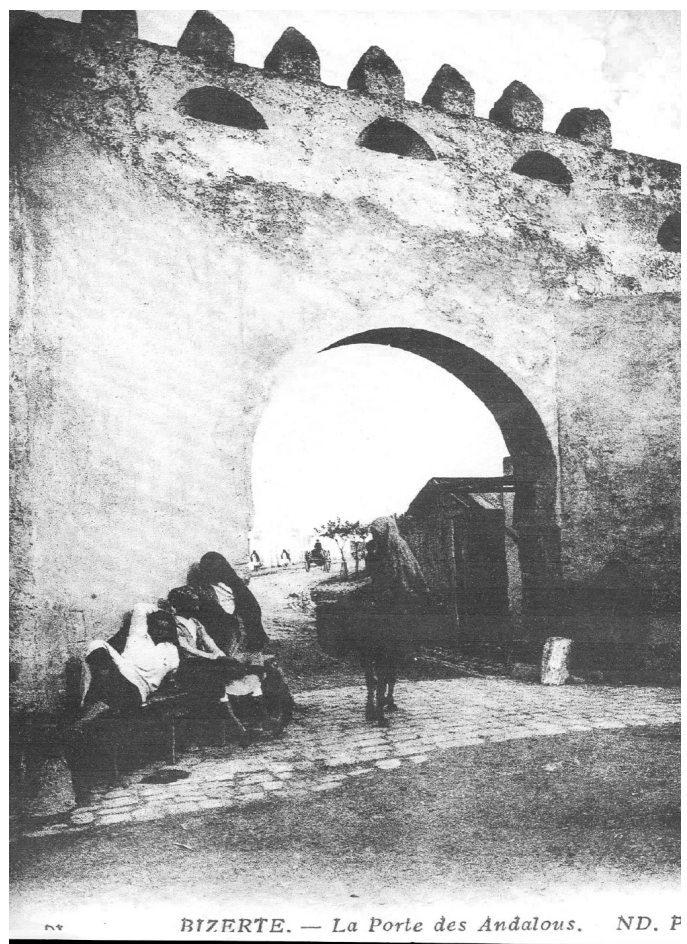

Este fuerte, que pudo contener 200 jenízaros según las informaciones de Lanfreducci y Bosio, confirmados por Salvago en $1624^{53}$, destacaba de la muralla de la ciudad. Desafortunadamente, tanto la muralla como el fuerte han sufrido bastante en avatares bélicos, después de la llegada de los moriscos, durante la Segunda Guerra Mundial, la batalla de Bizerta en $1961^{54}$ y durante las obras de restauración realizadas antes de que asumiera la dirección de obra en 1992.

En conclusión, puedo decir que el impacto de los moriscos fue importante en Bizerta, a partir de los documentos estudiados. La inscripción descubierta en una zona dominada por estos supone un testigo incontestable. El fuerte de los Andalusíes, la puerta de los Andalusíes, el barrio de los Andalusíes, con su mezquita de los Andalusíes y la fuente de los Andalusíes, desaparecida hoy día, se conservan aún en la memoria colectiva de los habitantes actuales y en unos documentos del siglo XIX, lo que indica la presencia e impacto de los moriscos o tagarenos en Bizerta.

53. N. Dougui et al., op. cit., p. 78.

54. A. MenajA, La bataille de Bizerte, Túnez, 1984, p. 68. 


\section{RESUMEN}

A partir de la noticia del primer descubrimiento de una lápida funeraria de un morisco en Bizerta, se analiza la presencia y el impacto de los moriscos y sus descendientes en esta zona de Túnez desde perspectivas históricas, demográficas y urbanísticas.

Palabras clave: moriscos, Túnez, Bizerta, tagarenos.

\section{ABSTRACT}

Notice the first discovery of a tombstone of a Morisco in Bizerte. The work analyzes the presence and impact of the Moriscos and their descendants in this area of Tunisia from an historical, demographic and urban perspective.

Key words: Moriscos, Tunis, Bizerta, Tagarins. 